\title{
Global Relapse in Viscera
}

National Cancer Institute

\section{Source}

National Cancer Institute. Global Relapse in Viscera. NCI Thesaurus. Code C159968.

New organ involvement in those with complete response. 